\title{
An Efficient Integration of Knowledge Management and E-learning in a Portable Interactive System
}

\author{
Folasade Olubusola Isinkaye ${ }^{1}$, Jumoke Soyemi ${ }^{2}$, Adedoyin Olayinka Ajayi ${ }^{1}$, \\ Amonatullahi Akorede Ismail ${ }^{1}$ \\ ${ }^{1}$ Department of Computer Science, Ekiti State University, Ado-Ekiti, Nigeria \\ ${ }^{2}$ Department of Computer Science, Federal Polytechnic, Ilaro, Nigeria
}

Email address:

adedoyin.ajayi@eksu.edu.ng (A. O. Ajayi)

\section{To cite this article:}

Folasade Olubusola Isinkaye, Jumoke Soyemi, Adedoyin Olayinka Ajayi, Amonatullahi Akorede Ismail. An Efficient Integration of Knowledge Management and E-learning in a Portable Interactive System. International Journal of Intelligent Information Systems. Vol. 10, No. 3, 2021, pp. 23-30. doi: 10.11648/j.ijiis.20211003.11

Received: April 18, 2021; Accepted: May 20, 2021; Published: June 16, 2021

\begin{abstract}
The advent of the internet made it possible to have access to unlimited e-learning resources for knowledge acquisition. Presently, there is an interest to introduce Knowledge Management (KM) into e-Learning with the hope that KM can facilitate an improved e-Learning system. The integration of an e-Learning system with KM is usually referred to as knowledge resource repository, with the KM methods implemented to increase the effectiveness of knowledge dissemination. The importance of KM cannot be over emphasized in any economy and that informs why it is acknowledged as a simplified tool for distributing and utilizing knowledge in a way that directly influence performance in any organization. Also, the potentials and necessity of e-learning in building and developing human capacity cannot be overstressed. Researchers have designed many models for integrating knowledge management into the e-learning system. Some were practically implemented while some were not. Despite the various models, researchers are still looking for a more interactive, efficient, and effective methods that could be used to quickly identify the most relevant information (knowledge) and distribute them to meet the specific needs of users. This work reviewed different literature on e-learning, Knowledge Management and their integration. It also implemented the integration of e-learning and Knowledge Management in a portable interactive system.
\end{abstract}

Keywords: Knowledge Management, E-learning, Personalization, Model, Integration, Portable

\section{Introduction}

The introduction of knowledge management (KM) and elearning (EL) has visibly brought the two areas nearer and hence encouraged their incorporation [1]. Also, the progress of e-learning and its improved facilities has motivated significant modifications in knowledge Management (KM) practices in various organizations [2]. Recently, learning has taken a new dimension from the formal learning environment of face to face learning to more flexible learning such as elearning. Cross [3], noted that over $80 \%$ of learning is now done outside the formal classroom learning. E-learning is a formal and systematic planned teaching and learning event where the teacher and the learner utilize Information Communication Technology (ICT) to enable interaction and collaboration $[4,5]$. Benefits of e-learning include time and space independence, learning can be done at the pace of the learners, learning contents can be organized and stored in a location and accessed globally. E-learning system allows personalization of content as well as creating profiles of users according to their learning patterns [1]. E-learning delivery can come in different forms like, Web-Based Training (WBT), electronic support systems, Computer-Based Training (CBT) [6], listservs, webcasts, interactive broadcasts, discussion forums, to mention a few. Knowledge Management, on the other hand, manages the processes that oversee the creation, utilization, and distribution of knowledge through technologies, structures, and people to 
generate the most effective learning, solve problems and make available timely decision making [4, 7]. Quality knowledge management is crucial and vital to the success of any organization hence, various organizations utilize information and communication technologies to implement their knowledge management systems (KMS) so as to improve the effectiveness of the knowledge management [8]. Also, learning and managing learning are now critical to the success of any organization. Therefore, the need to manage knowledge effectively is getting quite a wide attention. Knowledge management technologies are presently employed for rapid capturing, organizing, and delivering big amounts of corporate knowledge. Several companies embrace the initiative of knowledge management to bring to fore the sharing and integration of knowledge [9, 10].

The integration of e-learning and KM further facilitates improved organizational learning [11]. The problem of learning in a knowledge society is not restricted to helping learners acquire knowledge and skills effectively, but in managing, working with creativity and ideas and contributing to the creation of new knowledge [12]. This study reviewed different literature on e-learning system, Knowledge Management and their integration. The study also implemented an integration of e-learning and knowledge management within a portable system.

\section{Related Works}

E-learning or virtual learning is described as a technique for creating learning experience with the use of electronic technologies such as internet or intranet, video conferencing or satellite broadcasts. It is now a common style for improving both academic and professional skills of individual [13]. Also, e-learning enhances the quality of face to face delivery as it enables students to access course content independently [14]. E-learning systems uses different analytical tools and models which help to learn students' performance and as well comprehend their distinct patterns and hence increase their learning experience [15]. Also, the e-learning tools can equally assist tutors to monitor the activities of students in an E-learning environment [16]. Other benefits of e-learning include access to dynamic course content, efficient teaching which could be structured or unstructured can be employed wherever e-learning activities are carried out [16]. The success of E-learning depends on the capability and effectiveness of its knowledge management. Knowledge management helps organizations to create, store, transform and exchange knowledge within the organization [17]. Knowledge management (KM) has gain prominence because of its success in a wide range of organization, such as higher institution of learning [18]. So, the lack of integration of Knowledge management and Elearning in an organization will reduce the productivity of such organization.

For instance, Schmidt [19] implemented a KM and elearning model using context-aware technique for corporate learning. it involved two different paradigms leading to two different systems. The KM and EL integration were done using the user/learner context as the connecting means. This model was implemented in some prototype environments demonstrating reasonably high user acceptance. The model was evaluated and proves that integrating the functionalities of e-learning and knowledge management has the capacity of improving workplace learning. Nevertheless, to implement in the real sense, organizations are required to aid the services of general user context management to assist with the task of user context acquisition and management. In the work of Judrups [1], seven models for KM and e-learning integration were proposed, where only one of the models developed was implemented with relatively good user acceptability but requires implementation support for general use. Woelk and Agarwal [20] in their study attempted to develop an interactive and efficient model that integrates knowledge management into the e-learning system. The model gave insight into $\mathrm{KM}$ and e-learning integration capabilities. Woelk and Agarwal model was based on Nonaka and Takenuchi [21] SECI model using knowledge conversion involving four phases - socialization, externalization, combination, and internalization. This study further included two additional phases to SECI model - cognition and feedback. Knowledge Holder capable of creating explicit knowledge as well as storing in a knowledge repository or move the tacit knowledge to Knowledge seeker through socialization. However, the model developed was theoretical, and lack applicability support. Maier and Schmidt [22] proposed a knowledge maturation procedure as a conceptual framework to organize the requirement for the integration procedures. Knowledge maturation procedure was displayed in the form of a conceptual model that analyzes and explains the disruptions in the flow of organization and individual knowledge. The noted disruptions share the fragmented IT environment and organization structure facilitating knowledge of various levels of maturity. However, the model developed was purely theoretical and requires further support for real-life application and validation. Also, Mason [23] implemented InterCog sense-making model (ISMM) to integrate $\mathrm{KM}$ and e-learning by combining dimensions of knowing for analysis and understanding common areas of elearning and knowledge management. Model usability includes creating a strategic method to plan, develop, implement, and e-learning standards. The key point here is on inter-relationship relating to learning, knowledge, and thinking. Context is made up of simple questions such as "Who, What, When, Where, How, Why, and If", simplifying the whole process while maintaining a complex view. The model is however theoretical.

Islam and Kunifuji [24] proposed increasing the efficiency of e-learning by combining the personalized learning model with $\mathrm{KM}$ knowledge conversion methods to convert tacit knowledge to explicit knowledge. The model presented is, however, a theoretical one when dealing with KM and elearning integration. Ungaretti and Tillberg-Webb [25] used a dynamic learning system model to integrate $\mathrm{KM}$ and elearning by adding assurance of learning. The 
word "Assurance of learning" describes the systemic, deliberate procedure that reveals desired learning with the procedures required to determine the achievement and the improvement of the learning and the procedure for attainment. The dynamic learning system model comes from common elements of knowledge management, e-learning, and assurance of learning value chains, divided into four phases. The model also requires applicability support, better model elaboration, and validation. The model is not applicable in real-life situations.

Sivakumar [26] used an integrated e-learning design framework to disseminate knowledge. It shows the adaption of the KM method to e-learning. The framework identified the key factors for e-learning system design but lacks importance and critical assessments of such factors. This framework remained a theoretical approach outside the required guidelines for e-learning system design.

In this study, however, an effective system that integrated $\mathrm{KM}$ and E-learning was implemented to confirm its practicability as well as workability.

\section{Description of the Integration of Knowledge Management and E-learning System}

The essence of the integration of Knowledge Management and E-learning is to make e-learning system more speedy, effective, interactive, and well-organized. This requires replacing the duties of Knowledge Organizer (KO) and Instructional designer (ID) with Inference Engine (IE). The Inference Engine in this regard is responsible for organizing the knowledge that is deposited by the knowledge holder (lecturer) into the repository as well as organizing the learning modality based on some predefined conditions before knowledge seekers (student) can access it from the repository and make use of it. It is worth mentioning that the introduction of the Inference Engine into the system assists the result of the system to be more accurate, remove data redundancy, ensure data integrity, prevent duplication of data, and present timely results. Figure 1 shows the model of the proposed system.

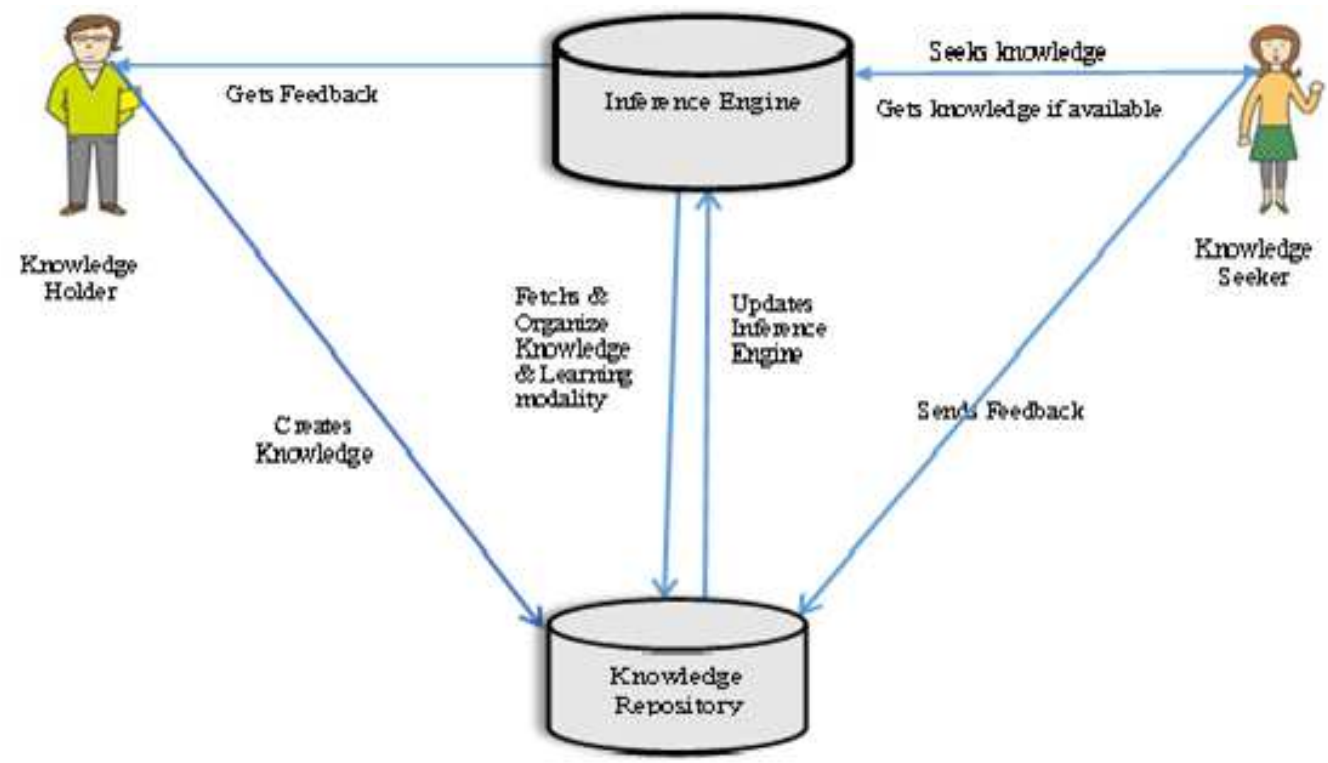

Figure 1. Knowledge Management and E-learning System.

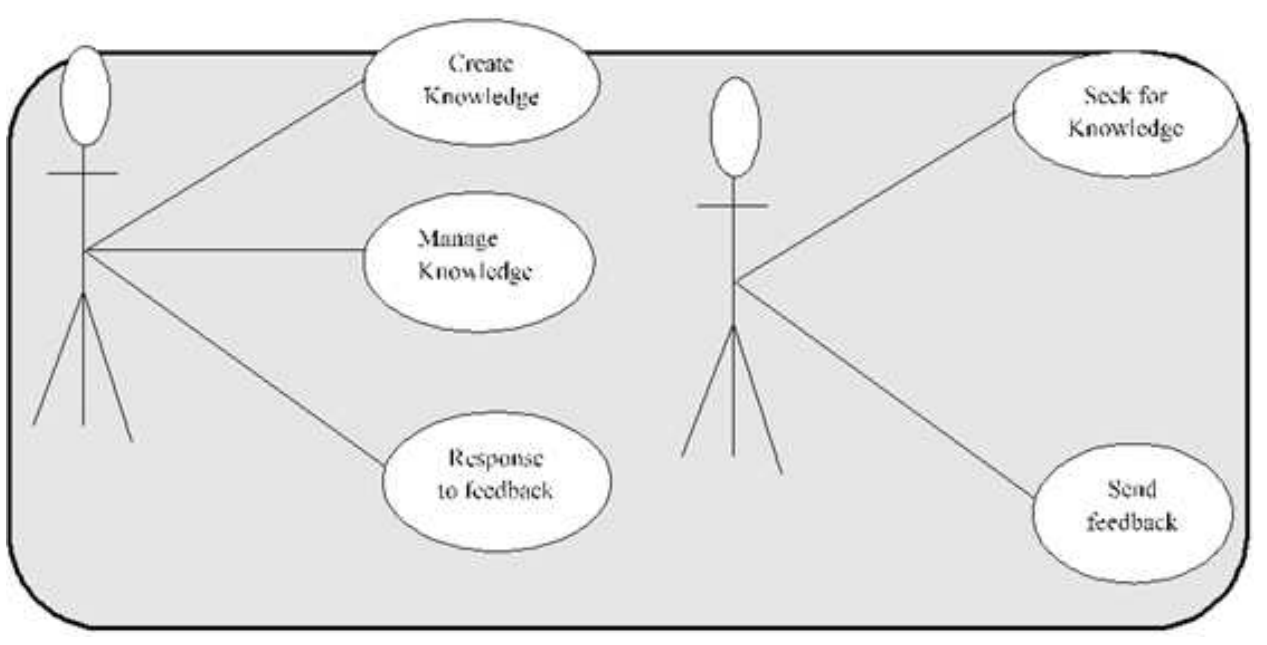

Figure 2. Use case Diagram of the Knowledge Holder and the Knowledge Seeker. 


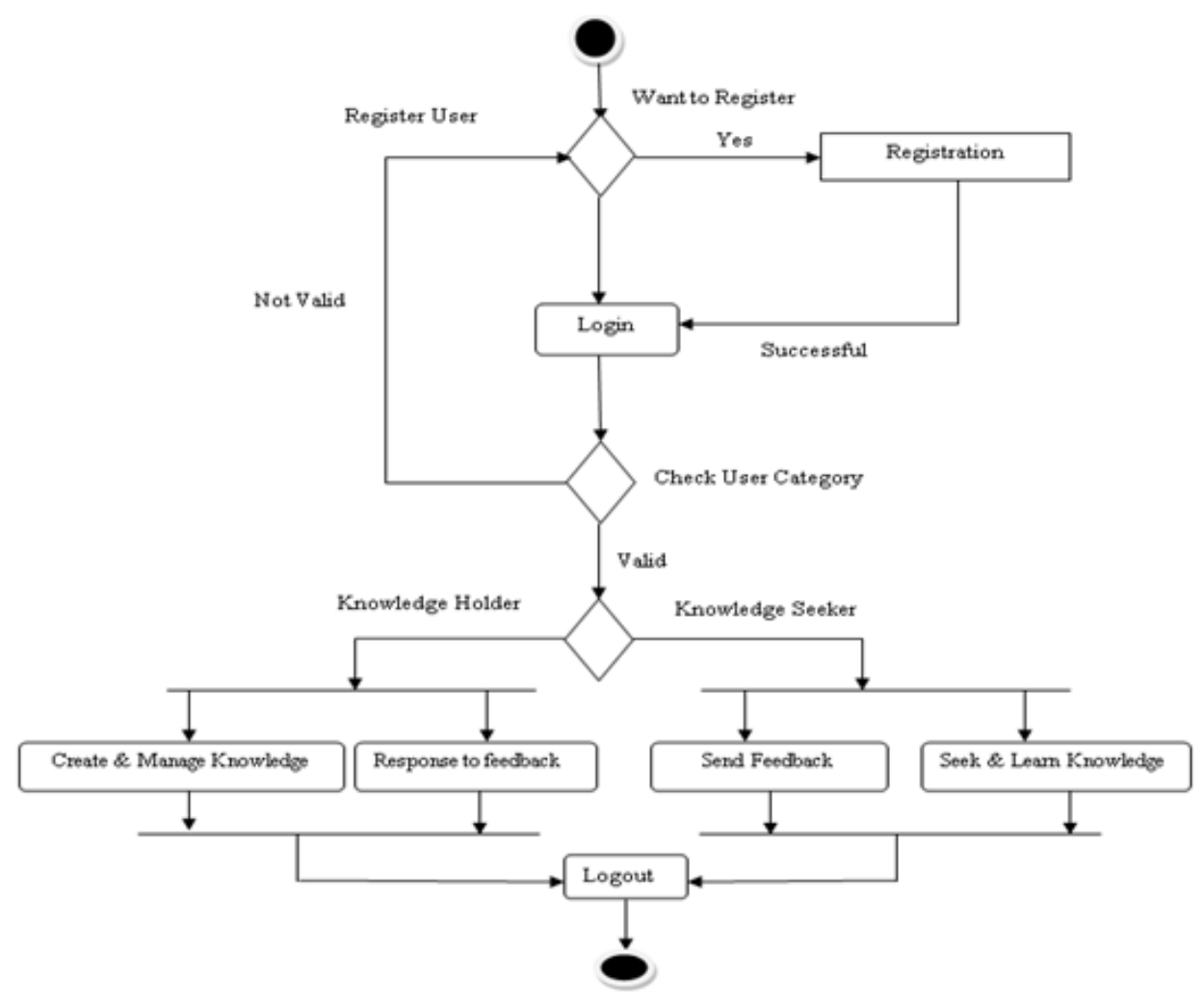

Figure 3. Activity Diagram of the Knowledge Management and E-learning System.

In the system, the knowledge holder create knowledge directly into the knowledge repository, the Inference Engine checks if knowledge exists in the knowledge repository. If exist, it organizes the knowledge base on the category they belong to, otherwise it returns false. The knowledge seekers only have access to the knowledge deduced from the Inference Engine. The knowledge seeker can also send feedback to the knowledge holder when necessary. The Inference Engine also take responsibility for organizing the feedbacks base on the required knowledge. The Inference Engine always checks the knowledge repository and update itself to provide accurate, and latest knowledge/feedback to the knowledge seeker. Figure 2 shows the use case Diagram of the Knowledge holder and The Knowledge seeker while Figure 3 shows the activity diagram of the proposed system. From figure 2, the Knowledge holder $(\mathrm{KH})$ and Knowledge seeker (KS) must be registered on the system before they can make use of it. After registration, the Inference Engine determines the category the registered user belongs and positions them into the appropriate categories. It is also worth mentioning that knowledge seekers are restricted to their domain alone, that is, they can only perform activities that are within their module.

\subsection{The Inference Engine and the Rules}

The objective of incorporating the Inference Engine into the existing system is to replace both the Knowledge and Instructional Organizers so as to enhance the speed up the system and hence make it more efficient. The conventional method of programming executes codes sequential following a fixed execution step. However, in the Rule-Based Inference method of programming, the next step of code execution is determined by available knowledge contained in the system. The rules of the Inference Engine for the Knowledge Management system are as follows.

1. start the system

2. register on the system

3. if imputes are correct proceed, else GOTO 2

4. categorize users to the appropriate places

5. login to the system

6. Validate login details.... If login is valid proceed, else GOTO 5

7. if user is $\mathrm{KH}$ proceed else GOTO 10

8. if option $=$ create knowledge, create knowledge, else GOTO 9

9. response to feedback

10. KS ... if option $=$ seek for knowledge

11. check if knowledge exist... if exist proceed, else GOTO 13

12. seek for knowledge or give feedback

13. end

\subsection{Knowledge Repository}

The knowledge repository here for managing knowledge and also providing services that include collection, organization, as well as knowledge retrieval. A knowledge repository can use many databases or can combine or enrich the database with information from public data sources. Hence, a knowledge repository is a huge and diverse source for many kinds of information. The knowledge repository in 
this context is where the knowledge holder creates or deposits knowledge for the knowledge seeker to utilize. The following is the rule or algorithm for the knowledge repository and knowledge holder.

1. Check knowledge holder access details

2. If valid, proceed and create knowledge else GOTO 1

3. Validate the created knowledge

4. If valid proceed, else GOTO 2

5. Check the category of the knowledge

6. If knowledge is for class A, deposit the knowledge in category A

7. If knowledge is for class $\mathrm{B}$, deposit the knowledge in category B

8. If knowledge is for class $\mathrm{C}$, deposit the knowledge in category $\mathrm{C}$

9. If knowledge is for class $\mathrm{D}$, deposit the knowledge in category D

10. Validate, if valid deposit else GOTO 5

11. End

The algorithm for the knowledge repository and knowledge seeker are expressed as follows:

1. check if knowledge seeker access details

2. if access valid proceed, else GOTO 1

3. seek for knowledge

4. if knowledge is available proceed, else GOTO 3

5. acquire knowledge

6. end

\section{Implementation of the Proposed System}

\section{System Implementation}

The System developed an integration of knowledge management and an e-learning system. where PHP was used as the programming language for the system. For the server side, MySQL was used as the Relational Database Management System (RDBMS). XAMPP was used as a local server because it helps to run apache, MySQL, and activate PHP queries.

Screenshots of the Implemented System

The welcome page is the first page to display when the application is launched. The welcome page allows the user to register/login as a student (knowledge seeker) or lecturer (knowledge holder). Figure 4 showed the welcome page of the system (AMID).

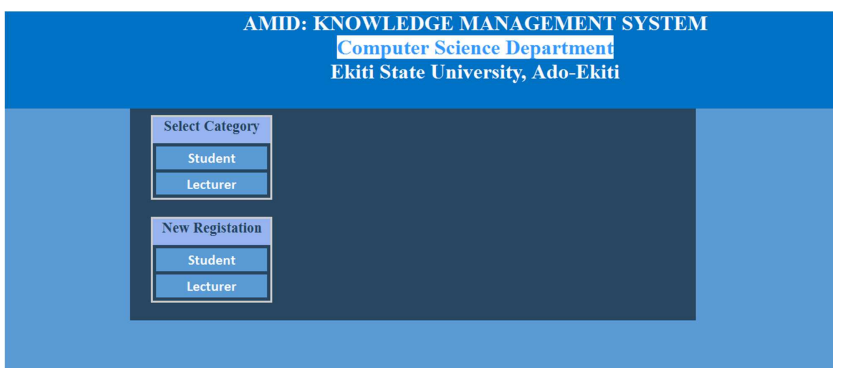

Figure 4. The Welcome Page.
The registration page allows the user to register on the system in order to have access to the system. More so, the system has a lecturer (knowledge holder) registration page and student (knowledge seeker) registration page. The lecturer registration page allows the lecturers to select which level and course are they taking and also allow them to create a username and password. Besides, the Student registration page provides the student to choose his level and create password. However, their matriculation number serves as their username. Figure 5 and Figure 6 show the lecturer (knowledge holder) registration page and student (knowledge seeker) registration page respectively.

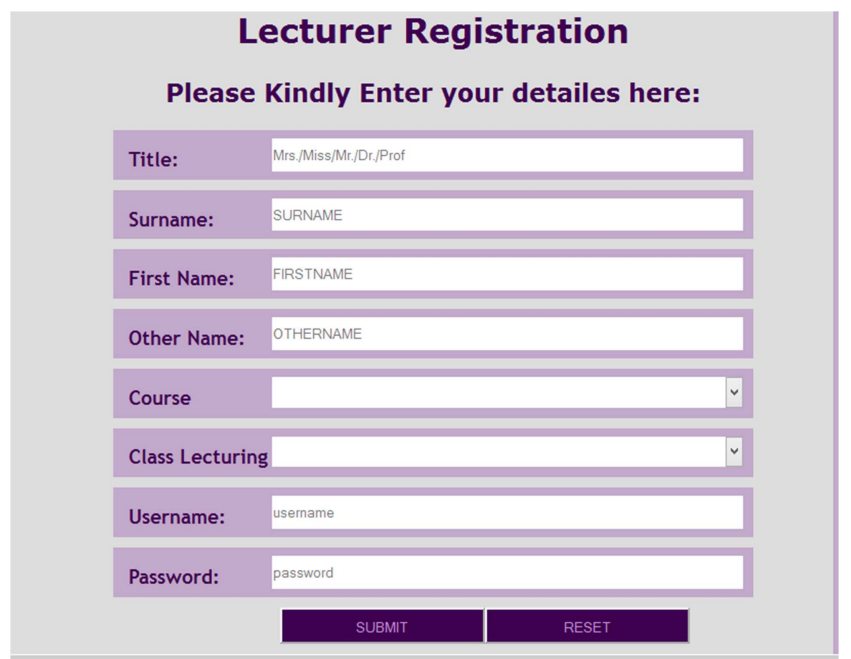

Figure 5. Knowledge Holder Registration Page.

\section{Student Registration}

Please Kindly Enter your detailes below:

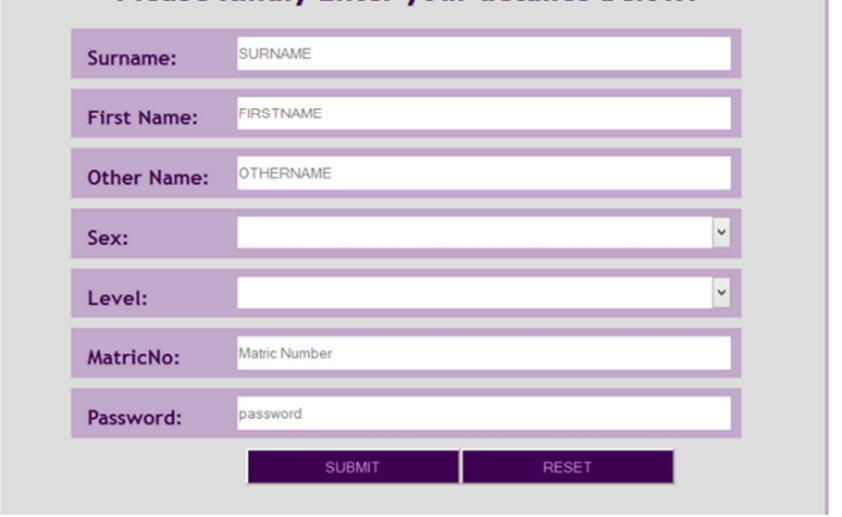

Figure 6. Knowledge Seeker Registration Page.

The Knowledge Holder (Lecturer) Page allows knowledge holders to perform is tasks; create, evaluate, disseminate knowledge, and receive feedback from knowledge seeker. The page also links to several pages that allow knowledge holders (lecturer) to publish course material, post information, give an assignment and view their student (knowledge seeker) as well. Figures 7, 8, 9, 10, and 11 show the interface of knowledge holder (lecturer), publish course material, post information, give an assignment, and view student (knowledge seeker) respectively. 


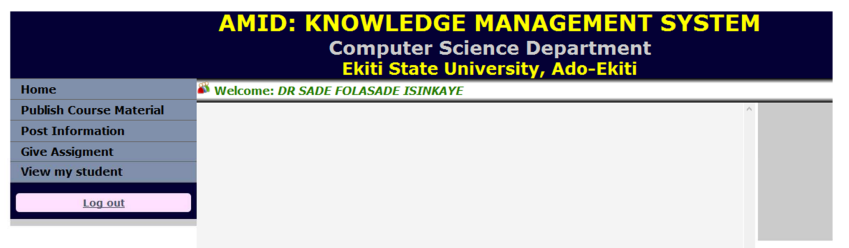

@2016 | All Rights Reserved

Figure 7. Knowledge Holder Page.

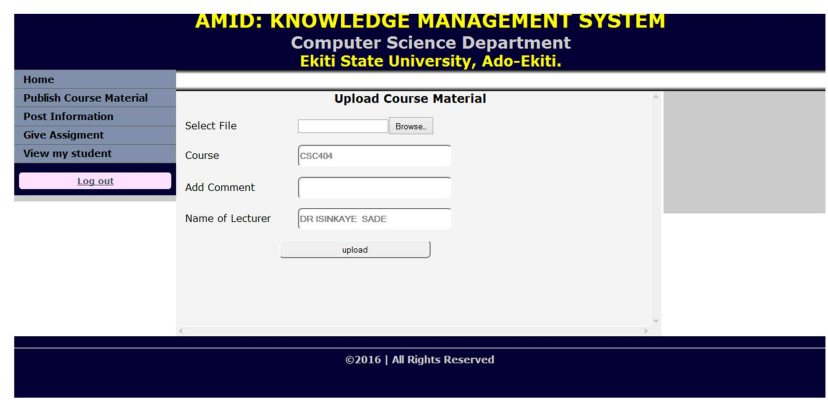

Figure 8. Publish Course Material Page.

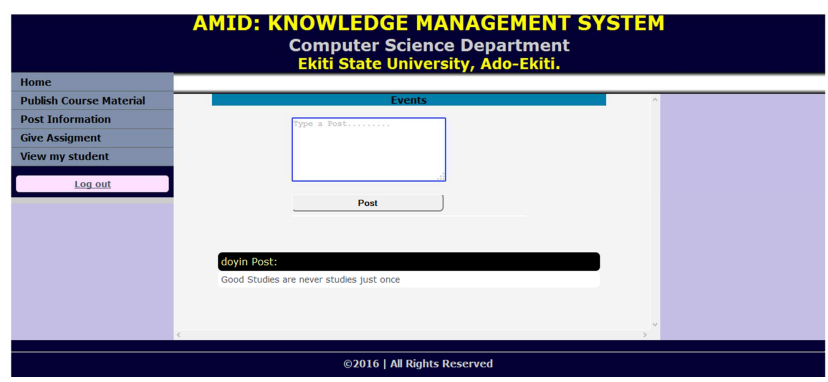

Figure 9. Post Information Page.

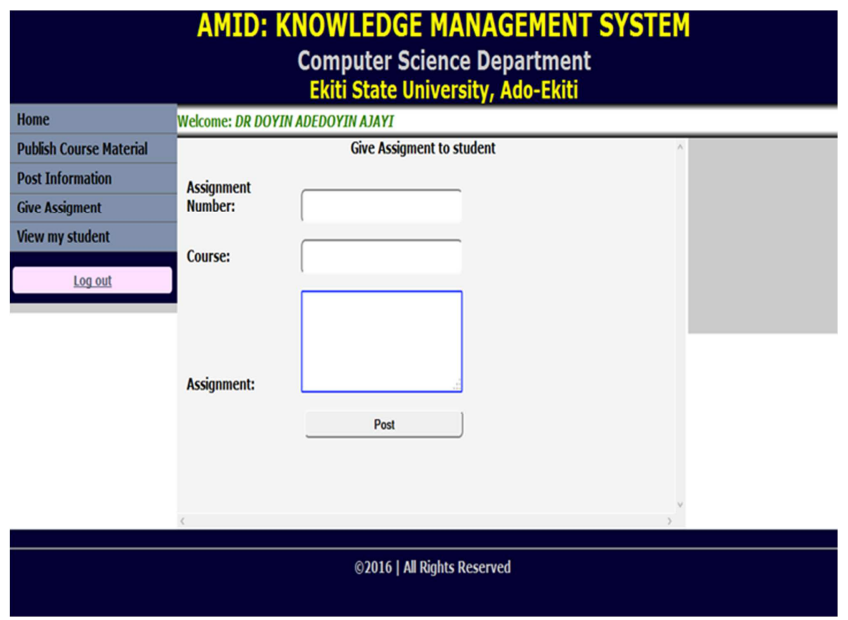

Figure 10. Assignment Page.

Knowledge Seeker Page (Student) permit knowledge seeker (Student) to have access to the knowledge shared by the knowledge holder (Lecturer) and allow Knowledge seeker (student) to summit assignment given to them. More so, the page also links to several pages that allow knowledge
Seeker (Student) to download materials, and chat page where Knowledge seeker can communicate with other seekers (students) in other to improve tacit knowledge transfer. Figures 12, 13, 14 and 15 show the interface of Knowledge seeker (Student), study area where students can download materials, chat room and submitted assignment respectively.

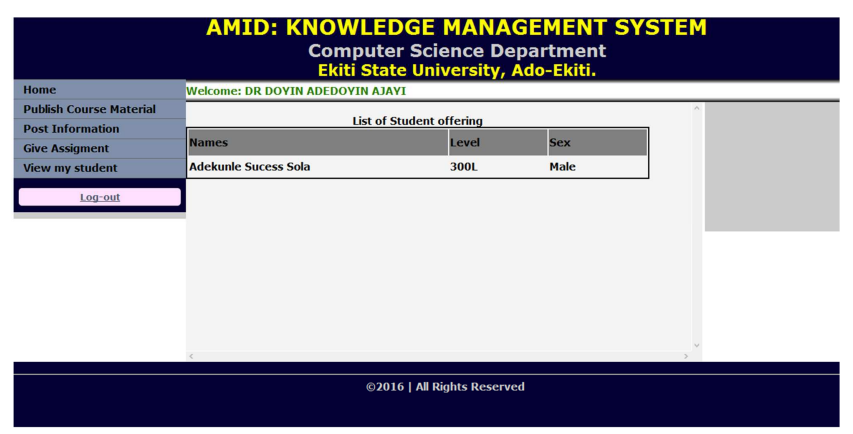

Figure 11. View Knowledge Seekers (Students) Page.

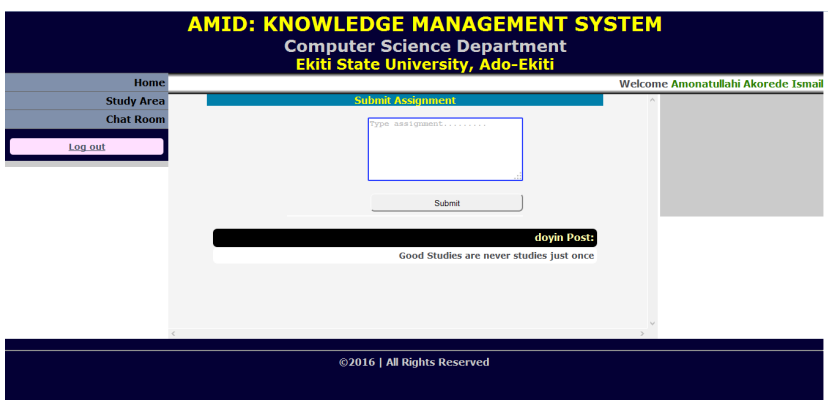

Figure 12. Knowledge Seeker Page.

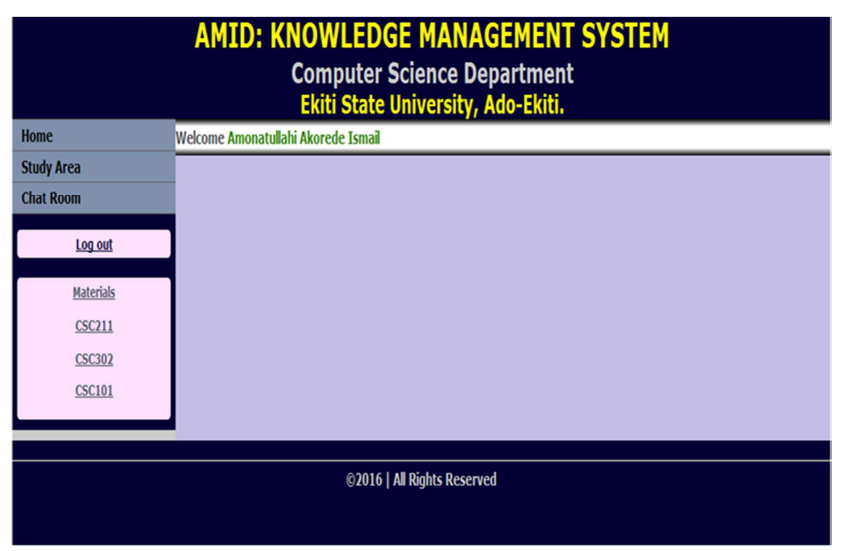

Figure 13. Study Page.

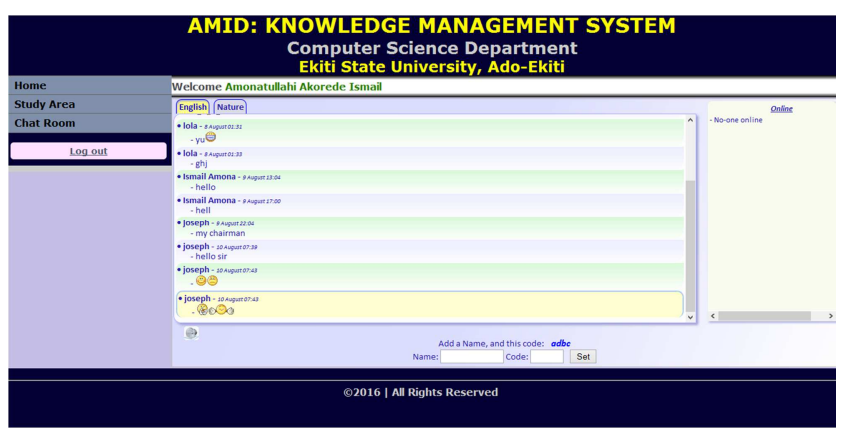

Figure 14. Chart Room. 


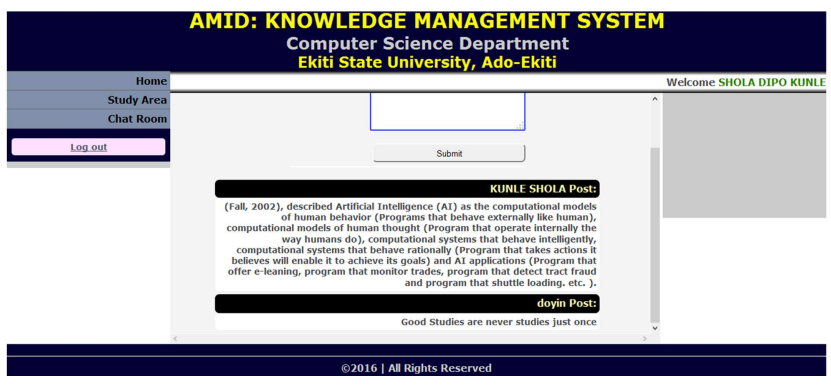

Figure 15. Submitted Assignments.

\section{Conclusion}

The advent of e-learning made unlimited sources of knowledge available to us all. Recent studies show great promise in the area of introducing Knowledge Management (KM) ideas to e-Learning systems. It is argued that KM can empower an e-learning system. The joint studies of KM and e-learning point out the fundamental goal of facilitating organizational learning. Therefore, this work implemented an efficient system that integrated Knowledge Management model and e-learning in a portable interactive system. The practicability of the system, its workability and effectiveness was thus established.

\section{References}

[1] Judrups, J. (2015). Analysis of knowledge management and elearning integration models. Procedia Computer Science, 43 (0), 154-162.

[2] Yordanova, K. (2007). Integration of knowledge management and e-learning: Common features. In Proceedings of the 2007 international conference on Computer systems and technologies (pp. 1-6).

[3] Cross, J. (2011). Informal learning: Rediscovering the natural pathways that inspire innovation and performance. John Wiley \& Sons.

[4] Sammour, G., Schreurs, J., Zoubi, A. Y., \& Vanhoof, K. (2008, September). Knowledge Management and eLearning in Professional Development. In the World Summit on Knowledge Society (pp. 178-183). Springer, Berlin, Heidelberg.

[5] Ojokoh, B. A., Doyeni, O. A., Adewale, O. S., \& Isinkaye, F. O. (2013). A Mobile-Based E-Learning System. International Journal of Web-Based Learning and Teaching Technologies (IJWLTT), 8 (3), 1-17. doi: 10.4018/ijwltt.201307010

[6] Qwaider, W. Q. (2011). Integrated of knowledge management and E-learning system. International Journal of Hybrid Information Technology, 4 (4), 59-70.

[7] Santoro, G., Vrontis, D., Thrassou, A., \& Dezi, L. (2018). The Internet of Things: Building a knowledge management system for open innovation and knowledge management capacity. Technological Forecasting and Social Change, $136,347-354$.

[8] Wang, Y. M., \& Wang, Y. C. (2016). Determinants of firms' knowledge management system implementation: An empirical study. Computers in Human behavior, 64, 829-842.

[9] Galagan, P. A. (2000). The e-learning revolution. Training \& Development, 54 (12), 24-24.

[10] Sabitha, S., Mehrotra, D., \& Bansal, A. (2015). Knowledge Enriched Learning by Converging Knowledge Object \& Learning Object. Electronic Journal of e-Learning, 13 (1), 313 .

[11] Khademi, M., Kabir, H., \& Haghshenas, M. (2011, September). E-learning as a Powerful Tool for Knowledge Management. In 5th International Conference on Distance Learning and Education (ICDLE 2011), Singapore.

[12] Wang, M., \& Yang, S. J. (2009). Knowledge management and E-learning. Knowledge Management \& E-Learning: An International Journal, 1 (1), 1-5.

[13] Chopra, G., Madan, P., Jaisingh, P., \& Bhaskar, P. (2019). Effectiveness of e-learning portal from students' perspective. Interactive Technology and Smart Education.

[14] Mtebe, J. S., \& Raphael, C. (2018). Key factors in learners' satisfaction with the e-learning system at the University of Dar es Salaam, Tanzania. Australasian Journal of Educational Technology, 34 (4).

[15] Ramos, D. B., Ramos, I. M. M., Gasparini, I., \& de Oliveira, E. H. T. (2021). A New Learning Path Model for E-Learning Systems. International Journal of Distance Education Technologies (IJDET), 19 (2), 20-40.

[16] Al-Rahmi, W. M., Yahaya, N., Aldraiweesh, A. A., Alamri, M. M., Aljarboa, N. A., Alturki, U., \& Aljeraiwi, A. A. (2019). Integrating technology acceptance model with innovation diffusion theory: An empirical investigation on students' intention to use E-learning systems. IEEE Access, 7, 26797 26809.

[17] Al-Jedaiah, M. (2020). Knowledge management and elearning effectiveness: Empirical evidence from Jordanian Higher Education Institutions. International Journal of Emerging Technologies in Learning (iJET), 15 (5), 50-62.

[18] Muhisn, Z. A. A., Ahmad, M., Omar, M., \& Muhisn, S. A. (2020). Knowledge internalization in e-learning management system. Telkomnika (Telecommunication Comput. Electron. Control, 18 (3), 1361-1367.

[19] Schmidt, A. (2005, April). Bridging the gap between knowledge management and e-learning with context-aware corporate learning. In Biennial Conference on Professional Knowledge Management/Wissensmanagement (pp. 203-213). Springer, Berlin, Heidelberg.

[20] Woelk Darrel and Agarwal Shallesh (2003) "Integration of eLearning and Knowledge Management" In: World Conference on E-learning in Corporate Government, Healthcare, and Higher Education, Vol. 2002, pp. 1035-1042.

[21] Nonaka I, Takeuchi H. (1995). The Knowledge-Creating Company: How Japanese Companies Create the Dynamics of Innovation. New York: Oxford University Press, USA.

[22] Maier, R., \& Schmidt, A. (2007). Characterizing knowledge maturing: A conceptual process model for integrating elearning and knowledge management. In 4th Conference Professional Knowledge Management-Experiences and Visions (WM'07), Potsdam. Volume. 
[23] Mason, J. (2008). A model for exploring a broad ecology of learning and knowing. In Supplementary Proceedings of the 16th International Conference on Computers in Education, Asia-Pacific Society for Computers in Education (APSCE) (pp. 194-203).

[24] Islam, M. S., Kunifuji, S., Miura, M., \& Hayama, T. (2011). Adopting knowledge management in an e-learning system: Insights and views of $\mathrm{KM}$ and EL research scholars. Knowledge Management \& E-Learning: An International Journal, 3 (3), 375-398.
[25] Ungaretti, A. S., \& Tillberg-Webb, H. K. (2011). Assurance of learning: Demonstrating the organizational impact of knowledge management and e-learning. Knowledge management and e-learning, 41-60.

[26] Sivakumar, S. C. (2011). E-Learning for Knowledge Dissemination. In Encyclopedia of Knowledge Management, Second Edition (pp. 249-262). IGI Global. 